\title{
Blonanserin-induced Mood Alteration in Schizophrenia and Schizoaffective Disorder: Two Cases
}

\author{
Aran Min, Daeho Kim \\ Department of Psychiatry, Hanyang University Medical Center, Hanyang University School of Medicine, Seoul, Korea
}

We report two outpatients, one with schizophrenia and one with schizoaffective disorder, who developed manic or hypomanic episodes following the initiation of blonanserin during the course of treatment. Blonanserin is a novel antipsychotic that acts as a $5-\mathrm{HT}$ and D2 receptor antagonist. Both patients developed hypomanic episodes within 2 weeks of receiving a small dose (6-8 mg) of blonanserin, and one patient later developed full-blown mania; both episodes ended within 1 month of discontinuing blonanserin. The mood alteration observed in these cases suggests a possible antidepressant effect of blonanserin; thus, clinicians should monitor mood changes when administering this antipsychotic.

KEY WORDS: Blonanserin; Bipolar disorder; Antipsychotic agents; Schizophrenia; Psychotic disorders.

\section{INTRODUCTION}

Although placebo-controlled studies suggest that atypical antipsychotic-induced mania or hypomania is a marginal phenomenon, case studies have reported manic/hypomanic symptoms following the administration of atypical antipsychotic drugs. ${ }^{1)}$ In fact, all atypical antipsychotics, with the exception of clozapine, have been reported to induce manic/hypomanic symptoms. ${ }^{2}$ The mechanisms underlying these mood alterations are not clearly understood; however, an antidepressant effect acting via 5HT-2A receptors may play a role. ${ }^{2}$ Nevertheless, case studies have certain limitations; the mood alterations may have resulted from the natural course of the bipolar illness, misdiagnosis, or a withdrawal effect from previous medication. ${ }^{1)}$ Thus, the emergence of mania/hypomania in a non-affective illness with no discontinuation of psychotropic medication to rule out a withdrawal effect would provide more convincing evidence of a causal relationship. Here, we describe two individuals with schizophrenia-spectrum disorders who developed mania and hypomania following the addition of blonanserin to

\footnotetext{
Received: March 14, 2013 / Revised: May 11, 2013

Accepted: May 16, 2013

Address for correspondence: Daeho Kim, MD, PhD

Department of Psychiatry, Hanyang University Guri Hospital, 153

Gyeonchunro, Guri 471-701, Korea

Tel: +82-31-560-2274, Fax: +82-31-554-2599

E-mail: dkim9289@hanyang.ac.kr
}

their medication regimen.

Blonanserin is a novel 5-HT2 and D2 receptor antagonist currently marketed in Japan and South Korea. Blonanserin has been shown to be as effective as risperidone and haloperidol in terms of positive symptoms and general psychopathology in four randomized clinical trials in people with schizophrenia. ${ }^{4)}$ Moreover, blonanserin had a better safety profile (e.g., lower incidence of hyperprolactinemia) compared with risperidone. ${ }^{5}$ No previous cases of blonanserin-induced mood alteration have been reported.

\section{CASE}

\section{Case 1}

A 25-year-old male with schizophrenia developed a hypomanic episode 1 week after the initiation of blonanserin at $8 \mathrm{mg}$ /day. He was first diagnosed with schizophrenia in 2003 at the age of 16 years with symptoms of auditory hallucination and delusions of reference and persecution and has been on various antipsychotic medications for 9 years. The patient did not achieve symptomatic remission, and his course was characterized by intermittent worsening and softening of the referential delusion that others were talking behind his back. He has been on a stable regimen of olanzapine 5-20 mg (final dose $10 \mathrm{mg}$ ), aripiprazole 15 $\mathrm{mg}$, clonazepam $0.5 \mathrm{mg}$, and benztropine $1 \mathrm{mg}$ since 2010. In February 2011, he experienced increased appetite

(c) This is an Open-Access article distributed under the terms of the Creative Commons Attribution Non-Commercial License (http://creativecommons.org/licenses/by-nc/3.0) which permits unrestricted non-commercial use, distribution, and reproduction in any medium, provided the original work is properly cited. 
and weight gain; thus, fluoxetine ( $20 \mathrm{mg}$ ) was added to his regimen for 7 months until September 2011 with no mood change.

In March 2012, the patient's ideas of reference began to increase and in May, he complained that his neighbors said bad things about him and that the rumors had spread throughout the community. Following this exacerbation, blonanserin $8 \mathrm{mg} /$ day was added to his regimen. Ten days later, the intensity of his delusions decreased, but he developed new symptoms indicative of a hypomanic episode, such as euphoria, elated mood, grandiosity, and hyperactivity. The patient expressed his plan to become a psychiatrist and he wrote poems for several hours per day with the intention of becoming a professional poet. He had a score of 19 on the Young Mania Rating Scale (YMRS). ${ }^{6}$ One week later blonanserin was withdrawn and the episode ended 4 weeks after discontinuation (YMRS score: $4)$.

\section{Case 2}

A 38-year-old male developed a manic episode after the initiation of blonanserin treatment. He first visited our outpatient department in May 2012 with complaints of persecutory and referential delusions that had developed 2 weeks earlier. He claimed that his colleagues at work bullied him and had hatched a plot to get him fired. His family reported that he accused his brother of being a spy from the company and called his father a North Korean spy. Furthermore, he showed bizarre behaviors such as wandering and picking up garbage. Schizophreniform disorder was suspected, and he was initially administered blonanserin $6 \mathrm{mg}$, alprazolam $0.375 \mathrm{mg}$, and benztropine $2 \mathrm{mg} /$ day. Shortly after receiving the medication, he displayed a slightly argumentative attitude and increased activity, but his behavior was considered to be within the normal range. Two weeks later, at a dose of 8-mg blonanserin, the patient reported that his persecutory and referential delusions were no longer valid, and he displayed a slight euphoria and increased psychomotor activity that met the criteria for a hypomanic episode.

Two weeks later, at $16 \mathrm{mg} /$ day blonanserin, the patient showed full-blown manic symptoms including talkativeness, hyperactivity, irritable and expansive mood, and flight of idea. He was considered for hospitalization but refused. He scored 27 on the YMRS. Valproate 500 $\mathrm{mg} /$ day was added to his regimen, and the dose of blonanserin was reduced to $12 \mathrm{mg} /$ day. His manic episode continued for 2 additional weeks; however, when blonanserin was discontinued his manic symptoms dis- appeared within 2 weeks (YMRS score: 2).

\section{DISCUSSION}

Here, we present two patients with schizophrenia and schizoaffective disorder who developed manic/hypomanic episodes following the initiation of blonanserin. Several factors may have contributed to this finding. Possible misdiagnosis of schizoaffective or bipolar disorder must be considered. Neither patient had a history of depressive or manic symptoms, although the second patient had a recent onset of psychosis and requires longterm follow up for future affective episodes. Furthermore, the effect of concurrent medication must be considered. The first patient's medication regimen was constant for several years with no change in mood, and he received fluoxetine for 7 months for weight control with no change in affect. The second patient received small doses of alprazolam and benztropine initiated concurrently with blonanserin; however, his manic episode ended following discontinuation of blonanserin while the other drugs were continued. Medications were not discontinued prior to the initiation of blonanserin in either patient, excluding the possibility of withdrawal effects.

Thus, the manic and hypomanic episodes observed in our patients were likely caused by blonanserin, which is supported by the fact that other atypical antipsychotics have been reported to induce mania. ${ }^{1,2)}$ The interval between medication initiation and the onset of the mood alterations must be considered. Both patients developed hypomanic symptoms within 2 weeks of receiving $8-\mathrm{mg}$ blonanserin. This interval is similar to that of risperidone (mean 15 days) and shorter than that of quetiapine (mean 19 days) and ziprasidone (mean 5 days). The very short initiation-to-effect interval of ziprasidone may explain, in part, the frequent emergence of hypomania following its administration; however, most of the cases occurred in patients with bipolar disorder. ${ }^{2)}$ It is not known whether the mood-altering effect of atypical antipsychotics is dose dependent. Small doses, such as 2-mg risperidone or 5-mg olanzapine, have been reported to induce mood changes. ${ }^{2)}$ Similarly, the hypomanic episodes observed in our cases began following administration of a small dose of blonanserin $(8 \mathrm{mg})$. Our second patient experienced mania after the blonanserin dose was increased to $16 \mathrm{mg}$. However, the worsening of symptoms after increasing the drug dose may be attributed to the natural course of the illness.

Previous case reports have suggested that discontinua- 
tion of a drug is the only action necessary to induce remission, particularly for hypomania. ${ }^{1,2)}$ However, other approaches, such as addition of a mood stabilizer or another atypical antipsychotic (e.g., quetiapine), have been used to end manic episodes. ${ }^{1)}$ Some patients respond to a reduction in the dose of the antipsychotic responsible for the mania; ${ }^{2)}$ however, our second patient did not improve following adding valproate or lowering blonanserin doses. His episode ended when we discontinued blonanserin, although there may have been a delayed effect of the low-dose valproate. Time to remission varies among studies and antipsychotic drugs. Our cases required 4 and 2 weeks, respectively to remit, whereas risperidone and olanzapine may take as long as several months. ${ }^{2)}$

The high affinity of atypical antipsychotics for the 5-HT2A receptors may underlie antipsychotic-induced mania/hypomania., ${ }^{2,7}$ Blonanserin is a 5-HT2A and D2 antagonist, ${ }^{8)}$ although its anti-5-HT2A activity has been reported to be lower than that of other atypical antipsychotics. ${ }^{9)}$ It is worth noting that blonanserin has successfully treated a case treatment-resistant depression. ${ }^{10)}$ Furthermore, a pooled analysis of clinical trials revealed a favorable effect of blonanserin on the negative symptoms of schizophrenia, suggesting a possible antidepressant effect of the drug. ${ }^{4}$

In conclusion, ours is the first case report showing blonanserin-induced mood alterations. Further studies are needed to investigate the effect and tolerability of blonanserin for bipolar and unipolar depressive disorders.

\section{REFERENCES}

1. Benyamina A, Samalin L. Atypical antipsychotic-induced mania/hypomania: a review of recent case reports and clinical studies. Int J Psychiatry Clin Pract 2012;16:2-7.

2. Michalopoulou PG, Lykouras L. Manic/hypomanic symptoms induced by atypical antipsychotics: a review of the reported cases. Prog Neuropsychopharmacol Biol Psychiatry 2006;30:549-564.

3. Deeks ED, Keating GM. Blonanserin: a review of its use in the management of schizophrenia. CNS Drugs 2010;24: 65-84.

4. Kishi T, Matsuda $\mathrm{Y}$, Nakamura H, Iwata N. Blonanserin for schizophrenia: systematic review and meta-analysis of double-blind, randomized, controlled trials. J Psychiatr Res 2013:47:149-154.

5. Yang J, Bahk WM, Cho HS, Jeon YW, Jon DI, Jung HY, et al. Efficacy and tolerability of Blonanserin in the patients with schizophrenia: a randomized, double-blind, risperidone-compared trial. Clin Neuropharmacol 2010;33:169175.

6. Young RC, Biggs JT, Ziegler VE, Meyer DA. A rating scale for mania: reliability, validity and sensitivity. $\mathrm{Br} J$ Psychiatry 1978;133:429-435.

7. Rachid F, Bertschy G, Bondolfi G, Aubry JM. Possible induction of mania or hypomania by atypical antipsychotics: an updated review of reported cases. J Clin Psychiatry 2004;65:1537-1545.

8. Ohno Y, Okano M, Imaki J, Tatara A, Okumura T, Shimizu S. Atypical antipsychotic properties of blonanserin, a novel dopamine D2 and 5-HT2A antagonist. Pharmacol Biochem Behav 2010;96:175-180.

9. Miyamoto S, Duncan GE, Marx CE, Lieberman JA. Treatments for schizophrenia: a critical review of pharmacology and mechanisms of action of antipsychotic drugs. Mol Psychiatry 2005;10:79-104.

10. Kumagai R, Ichimiya Y. Efficacy of blonanserin in combination therapy for treatment-resistant depression. Psychiatry Clin Neurosci 2009;63:593-594. 